\title{
Encoding metal-cation arrangements in metal-organic frameworks for programming the composition of electrocatalytically active multi-metal oxides.
}

\author{
Celia Castillo-Blas ${ }^{\dagger}$, M. Nieves López-Salas ${ }^{\dagger}$, María C. Gutiérrez ${ }^{\dagger}$, Inés Puente-Orench ${ }^{\ddagger}$, Enrique \\ Gutiérrez-Puebla $^{\dagger}$, M. Luisa Ferrer ${ }^{\dagger}$, M. Ángeles Monge ${ }^{\dagger *}$, Felipe Gándara ${ }^{\dagger *}$. \\ ${ }^{\dagger}$ Materials Science Factory, Instituto de Ciencia de Materiales de Madrid (ICMM) - Consejo Superior de Investiga- \\ ciones Científicas (CSIC), C/ Sor Juana Inés de la Cruz, 3, Madrid, Spain.
}

‡Univ. Grenoble Alpes, CNRS, Grenoble INP, Institut Néel, 38000 Grenoble, France

§Institut Laue Langevin, 71 avenue des Martyrs, CS 20156, 38042 Grenoble Cedex 9, France

KEYWORDS. Multication metal-organic frameworks, Oxygen reduction, spinel oxides.

\begin{abstract}
In the present contribution, we report how through the use of metal-organic frameworks (MOFs) composed of addressable combinations of up to four different metal elements it is possible to program the composition of multi-metal oxides, which are not attainable by other synthetic methodologies. Thus, due to the ability to distribute multiple metal cations at specific locations in the MOF secondary building units it is possible to code and transfer selected metal ratios to multi-metal oxides with novel, desired compositions through a simple calcination process. The demonstration of an enhancement in the electrocatalytic activity of new oxides by pre-adjusting the metal ratios is here reported for the oxygen reduction reaction, for which activity values comparable to commercial $\mathrm{Pt} / \mathrm{C}$ catalysts are reached, while showing long stability and methanol tolerance.
\end{abstract}

\section{INTRODUCTION}

Materials that are able to modulate their chemical composition through the combination of various elements while preserving their overall structure are scarce. Thus, the introduction of various metal elements in a same compound is synthetically challenging because typically a mixture of phases is obtained. ${ }^{1}$ In this context, metal-organic frameworks, MOFs, are demonstrating to be a suitable class of materials to combine multiple metal elements within a same structure type. ${ }^{2}$ MOFs are reticular materials formed by the joining of metal cations through organic linkers, giving rise to solids with extended, porous frameworks. ${ }^{3}$ In MOF chemistry, it is possible to introduce more than one metal cation within a given framework by following different synthetic approaches, ranging from post-synthetic transmetalation ${ }^{4-5}$ to one-pot synthesis with multiple cations. ${ }^{6-7}$ MOFs prepared with multiple metal cations exhibit properties that differ from their single-metal counterparts, such as enhancement in gas sorption selectivity, ${ }^{8}$ luminescent properties, ${ }^{9}$ mechanical properties, ${ }^{10}$ or catalytic activity. ${ }^{11-12}$ Recently, we have showed that MOFs offer a suitable platform to incorporate various combinations of metal cations in a controllable way within a same crystal structure. ${ }^{13}$ Judicious selection of inorganic secondary building unit (SBU), network topology, and initial molar ratios resulted in the formation of a series of isoreticular materials incorporating various metal-cation sequences formed by two or three elements. On the other hand, the use of MOFs as precursors to obtain other classes of solids though thermal treatment has emerged as an alternative to traditional synthetic routes, offering the possibility to transfer some of the MOF structural features to the resulting materials. ${ }^{14-16}$ In consequence, MOFs have been used to produce different types of metal oxides and metal oxide/carbon materials with unprecedented nanostructures, which find application in renewable energy technologies, such as metal-air batteries, fuel cells, and water electrolyzers through their use as catalysts for efficient and stable oxygen reduction reaction (ORR) and oxygen evolution reaction (OER). ${ }^{17-20}$

Following this line, in the present contribution we demonstrate that i) it is possible to produce MOFs incorporating complex metal arrangements composed of four different metal cations; ii) this compositional complexity emerging from the control on the cation arrangements can be translated to other classes of active solids by using MOFs as precursors. In particular, we show that thermal treatment of multi-metal MOFs with selected metal arrangements is an effective way to prepare multi-metal oxides with spinel structure and selected compositions; iii) the composition of the resulting spinel type oxides can be programmed from the MOF synthesis step, resulting in adjustment of their activity as electrocatalyst in the ORR. Consequently, we have prepared a series of oxides with spinel structure, some of them with compositions that have not been reported previously, including zinc, cobalt, manganese and calcium in the same material. Our results show that spinel type oxides with unprecedented compositions can be prepared from multi-metal MOFs following a simple thermal 
treatment, exhibiting catalytic activity that is comparable to that of commercial $\mathrm{Pt} / \mathrm{C}$ catalyst in terms of current density (97.2\%), preserving the activity after 5000 seconds, and without suffering from poisoning effects due to presence of methanol.

\section{EXPERIMENTAL SECTION}

\section{MOF synthesis}

General synthetic procedure for all the MOFs involve the dissolution of the selected metal salts and the organic linker in a water:ethanol:nitric acid solvent mixture, followed by heating at $170{ }^{\circ} \mathrm{C}$ overnight. An illustrative example of the synthesis procedure is given here for the compound with formula $\mathrm{Zn}_{0.23} \mathrm{Mn}_{\mathrm{0.44}} \mathrm{Co}_{0.33}$ (hfipbb): 4,4'-(hexafluoroisopropylidene)bis(benzoic acid) $\left(\mathrm{C}_{17} \mathrm{H}_{10} \mathrm{O}_{4} \mathrm{~F}_{6}, \mathrm{H}_{2}\right.$ hfipbb) (78 mg, o.2 $\mathrm{mmol}), \mathrm{Zn}\left(\mathrm{NO}_{3}\right)_{2} \cdot 6 \mathrm{H}_{2} \mathrm{O}$ (11 mg, $\left.0.047 \mathrm{mmol}\right), \mathrm{MnCl}_{2} \cdot 6 \mathrm{H}_{2} \mathrm{O}(29$ $\mathrm{mg}, 0.147 \mathrm{mmol})$ and $\mathrm{Co}\left(\mathrm{NO}_{3}\right)_{2} \cdot 6 \mathrm{H}_{2} \mathrm{O}(43 \mathrm{mg}, 0.147 \mathrm{mmol})$ were dissolved in $5 \mathrm{~mL}$ of distilled water and $5 \mathrm{~mL}$ of absolute ethanol and $300 \mu \mathrm{L}$ of a $1 \mathrm{M} \mathrm{HNO}_{3}$ solution. The mixture was stirred at room temperature for 5 minutes, placed in a Teflonlined steel autoclave, and heated at $170{ }^{\circ} \mathrm{C}$ overnight. After cooling to room temperature, blue needle shaped crystals were filtered off, washed with water and acetone, and dry under vacuum. Yield: $32 \mathrm{mg}, \mathbf{2 4} \%$ (based on linker). All other MOFs were similarly prepared using the amounts of metal salt specified in table $\mathrm{S} 1$, and keeping the same amounts of linker and solvents. The $\mathrm{CHN}$ and ICP analyses are contained in table S2.

\section{Multi-metal oxide synthesis.}

Multi-metal MOFs (10o mg) were subjected to a standard calcination process consisting of a thermal treatment in air, at $800{ }^{\circ} \mathrm{C}$ for 24 hours, with a heating rate of $2.5^{\circ} \mathrm{C} / \mathrm{min}$ in a zirconia crucible.

\section{Single crystal X-ray diffraction}

Crystals were selected with a polarized optical microscope for a single crystal X-ray diffraction experiment. Single crystal Xray data were collected in Bruker four circle kappa-diffractometers equipped with a $\mathrm{Cu}$ INCOATED microsource, operated at $30 \mathrm{~W}$ power $(45 \mathrm{kV}$, o.6o $\mathrm{mA})$ to generate $\mathrm{Cu} K \alpha$ radiation $(\lambda=1.54178 \AA$ ), and a Bruker VANTEC 500 area detector (microgap technology). Diffraction data were collected exploring over the reciprocal space in a combination of $\phi$ and $\omega$ scans to reach a resolution of $0.85 \AA$, with a completeness $>95 \%$, and redundancy $>3$. For this, either a generic quadrant collection strategy or a specific one determined using Bruker APEX3 software suite was used. The exposure time was adjusted based on the size and diffracting quality of the specimens, each exposure covering $1^{\circ}$ in $\omega$ or $\phi$. Unit cell dimensions were determined for least-squares fit of reflections with $I>4 \sigma$. The structures were solved by intrinsic phasing or direct methods, implemented in SHELX package. The hydrogen atoms were fixed at their calculated positions using distances and angle constraints. All calculations were performed using APEX $_{3}$ software for data collection and OLEX2-1.2. ${ }^{21}$ and SHELXTL ${ }^{22}$ to resolve and refine the structure. All non-hydrogen atoms were anisotropically refined. It should be noted that the chemical composition deduced from the X-ray diffraction data do not necessarily correspond with that of the bulk analytically determined, due to the close atomic number of the employed elements. Therefore, ID codes are given based on the $\mathrm{CHN} / \mathrm{ICP}$ analyses for all samples. Tables $\mathrm{S}_{3}$-S2o summarize the crystal and refinement data of all MOFs compositions.

\section{X-ray powder diffraction}

Powder X-ray diffraction (PXRD) patterns (figures $\mathrm{S}_{1}-\mathrm{S}_{3}$ and $\mathrm{S}_{15}$-S18) were measured with a Bruker D8 diffractometer with a copper source operated at $1600 \mathrm{~W}$, with step size $=0.02{ }^{\circ}$ and exposure time $=0.5 \mathrm{~s} / \mathrm{step}$ for MOFs measurements and step size $=0.016^{\circ}$ and exposure time $=1.5 \mathrm{~s} /$ step for calcination products.

\section{Neutron powder diffraction}

Neutron powder diffraction experiments were performed on the high-intensity powder diffractometer DiB and high resolution HRPT powder diffractometer at the Institut LaueLangevin in Grenoble (France) and Paul Scherrer Institut (Switzerland), respectively. The samples were contained in 5 $\mathrm{mm}$ cylindrical vanadium cans and placed inside a cryostat. The data sets were collected with calibrated neutrons of wavelengths 2.526o $\AA$ and $1.4939 \AA$ for DiB and HRPT, respectively.

\section{ORR activity}

The ORR activity was investigated using an Autolab PGSTAT $302 \mathrm{~N}$ with a three-electrode setup. A platinum mesh and an $\mathrm{Ag} / \mathrm{AgCl} / \mathrm{KCl}$ (o.1 $\mathrm{M}$ ) were used as counter and reference electrodes, respectively. The active material was prepared mixing $3.5 \mathrm{mg}$ of super $\mathrm{P}$ carbon black and $1.5 \mathrm{mg}$ of the corresponding catalytic oxide with $47.5 \mu \mathrm{L}$ of Nafion 177 and $117 \mu \mathrm{L}$ of absolute ethanol. The mixture was sonicated for 15 minutes. The glassy carbon rotating-disk-working electrode (RDE, $4 \mathrm{~mm}$ in diameter) was polished and coated twice, by drop casting, with $3.5 \mu \mathrm{L}$ of slurry. All electrochemical measurements, including cyclic voltammograms (CV), linear sweep voltammograms (LSV) on a RDE at a rotation rate of up to $2000 \mathrm{rpm}$ and chronoamperometry, were performed at room temperature in $0.1 \mathrm{M} \mathrm{KOH}$ solutions, previously purged with high purity either nitrogen or oxygen for at least 1 hour. Both $\mathrm{CV}$ and LSV were recorded at $10 \mathrm{mVs}^{-1}$ scan rate and the potential window ranged from o.o to $-0.8 \mathrm{~V}$. The stability and tolerance of the materials to methanol $\left(\mathrm{CH}_{3} \mathrm{OH}\right)$ crossover was studied by chronoamperometry measurements, which were performed at 1600 rpm over 5000 and upon the addition of $\mathrm{CH}_{3} \mathrm{OH}$ (o.3 $\mathrm{M}$ final concentration) to the $\mathrm{O}_{2}$-saturated o.1 $\mathrm{M} \mathrm{KOH}$ electrolyte.

\section{RESULTS AND DISCUSSION}

\section{The role of zinc as structure directing element in multi-metal complex MOFs}

In our previous work, we demonstrated that the incorporation of multiple metal elements within a same MOF crystal can be accomplished with control over the disposition of the metal cations. ${ }^{13}$ In particular, we showed that zinc, cobalt, manganese, and/or calcium can be combined in a SBU and their atomic arrangements in the SBUs addressed through the right combination of the initial molar codes (i.e., molar ratios), as consequence of the differences in the coordination environment of the selected metal elements. A series of isoreticular materials were prepared, with a structure based on the MOF 
known as ZnPF-1 (Zn-hfipbb), ${ }^{23}$ which consists of helical shaped inorganic SBUs composed of zinc atoms in tetrahedral coordination environment. Cobalt, manganese, or calcium atoms with octahedral coordination environment were introduced in the SBU, resulting in a change in the crystal symmetry, while preserving the original network topology (Figure 1). Furthermore, we found that cobalt atoms might be found in both tetrahedral and/or octahedral environment depending on the selected initial molar ratios, while manganese and zinc cations are exclusively in octahedral or tetrahedral coordination, respectively. These differences in the preferential environments for the metal cations allowed us to produce different metal cation arrangements in the inorganic SBUs. By adjusting the initial three-element molar code it is possible to address the location of cobalt cations in the SBUs. Following these findings, we decided to evaluate whether it would be possible to introduce different combinations of metal cations, with the ultimate goal of demonstrating that the metal arrangements and ratios might be translated to metal oxides after MOF calcination, as described below.

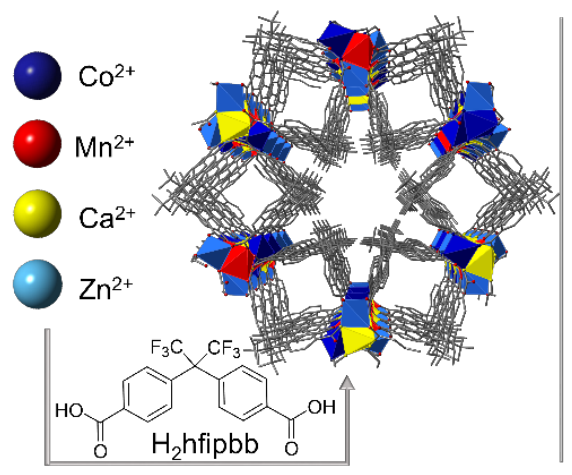

\section{SBU sequences}

2 metal cations

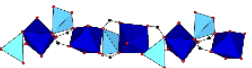

3 metal cations

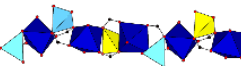

4 metal cations

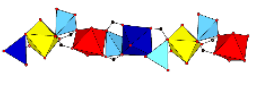

FIGURE 1. The multi-metal MOF is formed by the combination of different cations $\left(\mathrm{Zn}^{2+}, \mathrm{Co}^{2+}, \mathrm{Mn}^{2+}\right.$ and $\left.\mathrm{Ca}^{2+}\right)$ forming a helical inorganic SBU, and the organic linker $\mathrm{H}_{2}$ hfipbb (left). The helical shaped inorganic SBUs are formed by alternating tetrahedral and octahedral coordination polyhedra. The SBUs contain 2, 3 or 4 different metal elements (right).

All the previously reported members of this family of materials include zinc in their composition, as the addition of this element was found to be necessary to yield the desired MOF type, suggesting a structure directing role of this element. To study to what extend this is accurate, we first decreased the relative amount of zinc to produce MOFs with higher content of manganese and cobalt. Generally, when synthesis experiments were carried out with the use of either cobalt or manganese, and low amount or absence of zinc, other crystalline phases were obtained. ${ }^{12}$ However, we found that it is possible to obtain the same MOF topology in absence of zinc provided that cobalt and manganese are combined at appropriate ratios, although the product was obtained only with low yield (9 mg, 7\% based on ligand). A MOF was thus prepared from a Mn:Co 1:1 ratio with the resulting composition of $\mathrm{Mn}_{0.41} \mathrm{Co}_{0.59}$ (hfipbb). Single crystal X-ray diffraction analysis shows a unit cell in which the $c$ parameter is twice that of the ZnPF-1 MOF, and a SBU with alternating octahedral and tetrahedral sites (as it happens in previously reported $\mathrm{Zn}: \mathrm{Mn}$ and $\mathrm{Zn}$ :Co members of the series). Manganese atoms are in octahedral environment, while cobalt cations are mostly in tetrahedral one, with some of them in octahedral environment, partly replacing the manganese positions. Neutron powder diffraction analysis further

supports this metal cation arrangement, also showing that there is no temperature dependent structural change in the $298 \mathrm{~K}$ to $10 \mathrm{~K}$ range (Figure $\mathrm{S}_{4}$ ).

Despite this experiment shows that it is possible to obtain the same MOF topology in absence of zinc, the resulting yield is very low $(7 \%)$. Moreover, all other explored combinations of Co:Mn molar codes were not successful in obtaining this MOF type. Therefore, the role of zinc as structure directing element in the achieving of this MOF topology come out evident, being required to afford an inorganic SBU that otherwise has shown adaptability and dynamism for including multiple elements with variable coordination environments.

\section{Obtaining new ternary and quaternary multi-metal MOFs with programmed composition}

Based on the previous success preparing Zn-Mn-Co MOFs with various cation arrangements, we prepared five new ternary multi-metal MOFs combining Zn, Co, and Mn with new metal-cation ratios (table $\mathrm{S}$, entries 1-5). In line with our previous observations, and due to the different incorporation kinetic of the metal cations, it was necessary to start with a high amount of cobalt in order to obtain MOFs with a large content of this element in their composition. This is in contrast to the case of manganese, which is more homogeneously incorporated in all the cases.

In addition to ternary systems, we have now expanded the number of different cations that can be incorporated up to four elements. Previously, we already showed that calcium can be introduced in this MOF structure when combined with zinc and either cobalt or manganese. ${ }^{12}$ Now, we have synthesized eleven new quaternary multi-metal MOFs combining zinc, cobalt, manganese and calcium. Ultimately, we have prepared these materials to demonstrate that metal oxides with new compositions including these four elements can be produced from MOFs, and that their electrocatalyitc activity is subsequently enhanced. The employed molar codes and the resulting MOF formulae are given in table $S_{1}$, entries 6-16. In all cases, the resulting MOF structures exhibit SBUs where the cations are in octahedral and tetrahedral coordination environments, without any compositional gradient, as demonstrated by the neutron powder diffraction and SEM-EDS experiments (figures S6-S9 and $\mathrm{S}_{12}-\mathrm{S}_{14}$ ).

The analysis of the obtained metal arrangements shows that the combination of four elements in the initial molar codes results in a complex behavior with and interplay of the four cations, so that a direct relationship between input and output ratios is not evident. Use of an equimolar code (1:1:1:1) results in a low incorporation of calcium into the MOF with composition $\left[\mathrm{Zn}_{0.42} \mathrm{Mn}_{0.42} \mathrm{Co}_{0.11} \mathrm{Ca}_{\text {o.o6 }}(\mathrm{hfipbb})\right]$. Increasing the initial amount of calcium results in a larger incorporation of this element, although this increment is not linearly related to the starting amount, as demonstrated by the material prepared from a 1:1:1:7 molar code (table S1, entry 8). This can be explained by the fact that calcium atoms will only be occupying sites with octahedral environment in the SBU, which are readily occupied by manganese atoms. However, if the relative amount of calcium and cobalt are simultaneously increased, a higher incorporation of calcium is achieved. Thus, the MOF prepared from a 1:1:4:4 molar code exhibits a $\mathrm{Zn}_{0.18} \mathrm{Mn}_{0.24} \mathrm{Co}_{0.41} \mathrm{Ca}_{0.16}(\mathrm{hfipb})$ formula. This observation was consistent with our previous work, where we already found 
that in ternary $\mathrm{Zn}: \mathrm{Co}: \mathrm{Ca}$ systems the amount of calcium increased when there is larger presence of cobalt. ${ }^{13}$ We hypothesized with the fact that presence of cobalt - calcium pairs in the SBU might be favored over zinc - calcium ones. Indeed, the MOF with the largest amount of calcium was obtained in absence of zinc, and the material prepared from a $\mathrm{Mn}: \mathrm{Co}: \mathrm{Ca}$ 1:2:2 molar code has a $\mathrm{Mn}_{0.23} \mathrm{Co}_{0.50} \mathrm{Ca}_{0.27}$ (hfipbb) formula. Single crystal X-ray diffraction analysis shows a SBU with cobalt atoms in tetrahedral environment, and calcium and manganese atoms in octahedral coordination environment. This particular result seems to indicate that certain dyads of metal cations might also play a structure directing role analogue to zinc, although further experiments are necessary to confirm to what extend this can be generalized to other metal element combinations.

\section{Obtaining of multi-metal oxides with programmed composition through multi-metal MOF calcination}

Through our developed method to produce complex multimetal MOFs, we have in hand an array of materials with precise control of the metal cation distribution, which in principle could be advantageous to obtain oxides with compositions that are not attainable following other synthetic routes (Figure 2). Thus, we proceeded to expose the MOFs to a calcination process, and the structure type of the resulting oxide was analyzed with the use of PXRD (Figures $\mathrm{S}_{15}-\mathrm{S}_{18}$ ). Results of the obtained oxides are summarized in table S21.

Multi-metal MOFs were subjected to a standard calcination process (1), consisting of a thermal treatment in air, at $800{ }^{\circ} \mathrm{C}$ for $24 \mathrm{~h}$, with a heating rate of $2.5^{\circ} \mathrm{C} / \mathrm{min}$, to obtain the corresponding multi-metal oxides preserving the metal ratios.

$\stackrel{(1)}{\rightarrow} \quad 3\left[\mathrm{Zn}_{\mathrm{w}} \mathrm{Mn}_{\mathrm{x}} \mathrm{Co}_{\mathrm{y}} \mathrm{Ca}_{\mathrm{z}} \quad\left(\mathrm{C}_{17} \mathrm{H}_{8} \mathrm{O}_{4} \mathrm{~F}_{6}\right)\right]+\underset{\left.\mathrm{Zn}_{3 \mathrm{w}} \mathrm{Mn}_{3 \mathrm{x}} \mathrm{Co}_{3 \mathrm{y}} \mathrm{Ca}_{3 \mathrm{z}} \mathrm{O}_{4}\right)+{ }_{51} \mathrm{CO}_{2}+{ }_{3} \mathrm{H}_{2} \mathrm{O}+18 \mathrm{HF}}{+}+48.5 \mathrm{O}_{2}$

Thermal gravimetric analysis of the corresponding MOFs indicate that the decomposition of the materials occurs at 500 ${ }^{\circ} \mathrm{C}$, with no additional weight loss at higher temperature (figures $\mathrm{S}_{19}-\mathrm{S}_{21}$ ). Therefore, the organic linker is fully combusted at the employed calcination temperature. A CHN elemental analysis for calcined samples further confirmed the absence of any organic species in the resulting solids, which were additionally characterized with the use of SEM, TEM, PXRD, and EDS. Field emission SEM images show that the MOF crystals morphology is maintained in the resulting oxides after the heating process (figures S22-S24). ${ }^{24}$ The resulting solids are composed of crystallites of size in the range 30 to $2 \mu \mathrm{m}$, which are aggregated preserving the shape of the precursor MOF crystal (Figure 3). The SEM-EDS (figures S25-S27) and TEMEDS (figures S28-S29) analyses present consistent results and demonstrate a clear correspondence between the metal ratios in the aggregates and the individual particles (figure 4). For the sake of comparison, we also studied the MOF prepared with zinc as only metal cation (ZnPF-1). ${ }^{23}$ As expected, calcination of $\mathrm{ZnPF}-1$ resulted in the formation of wurtzite type oxide, according to the PXRD pattern (figure $\mathrm{S}_{15} \mathrm{~A}$ ).

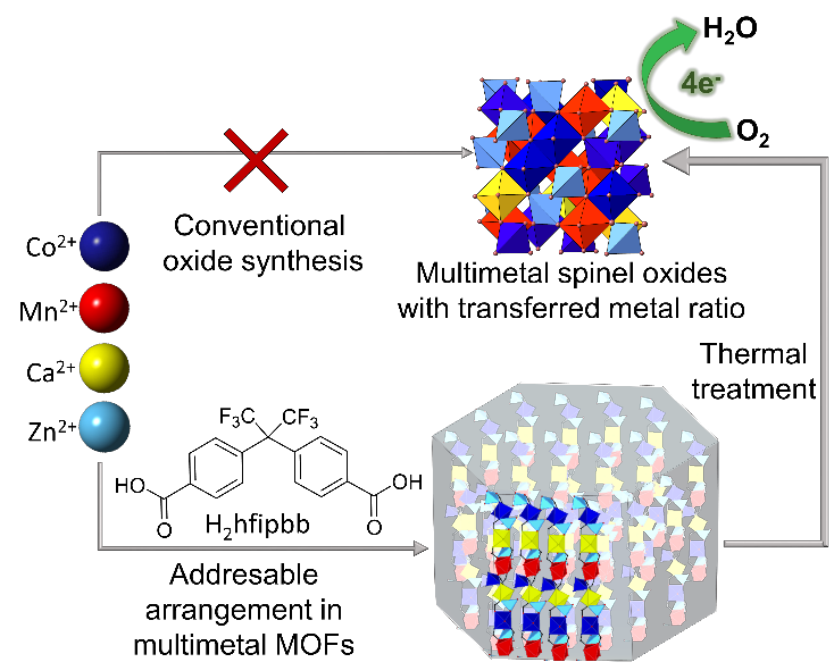

FIGURE 2. Thermal decomposition of multi-metal MOFs allow the obtaining of multi-cation oxides with compositions not attainable with conventional oxide synthetic routes. The metal ratios in the resulting oxides are transferred from their correspondent parent MOFs.

\section{Binary Zn:Co, Zn:Mn, and Zn:Ca systems}

Binary systems consisting of zinc and cobalt resulted in a mixture of crystalline phases, which were identified as wurtzite as major phase, mixed with spinel type oxide. Calcination of the MOF formed from $\mathrm{Zn}: \mathrm{Co}$ 1:10 molar code and formula $\mathrm{Zn}_{\mathrm{o} .21} \mathrm{Co}_{0.79}(\mathrm{hfipbb})$, results in the formation of cubic spinel oxide as major phase, although with presence of a small amount of wurtzite (figures $\mathrm{S}_{15} \mathrm{E}$ ). TEM and EDS analyses of this solid indicate that the formed oxide particles do not have a homogeneous composition. This is not surprising, as the parent MOF crystals exhibited a clear compositional gradient, with internal and external areas being rich in zinc or cobalt, respectively (figures S28A-C). Similarly, calcination of binary systems composed of zinc and calcium also resulted in formation of wurtzite oxide, and in the cases where there is a larger amount of calcium in the MOF, the presence of fluorite was also detected (figures $\mathrm{S}_{18 G}-\mathrm{H}$ and S28D-E). Calcination of the MOF formed from Zn:Mn 1:1 molar code resulted in a mixture of phases containing hetaerolite (tetragonal) and spinel (cubic) type oxides as major phases, as well as traces of other crystalline phases that could not be unambiguously identified (figure $\left.\mathrm{S}_{15} \mathrm{~F}\right)$.

\section{Ternary Zn:Mn:Co, Zn:Mn:Ca, Mn:Co:Ca systems}

On the other hand, the calcination of ternary multi-metal MOFs including zinc, manganese, and cobalt, resulted in the formation of spinel type oxides. When the initial Zn molar ratio was higher than 30 at $\%$, other crystalline phases were also detected in the PXRD patterns, (mainly wurtzite). By decreasing the amount of zinc in ternary multi-metal MOFs, we were able to obtain spinel type oxides as only product of the calcination process, as proved by the PXRD, SEM and TEM analyses. Thus, seven new multi-metal oxides with cubic spinel structure were prepared from the calcination of the corresponding multi-metal MOFs (figure $5 \mathrm{~A}$ and $\mathrm{S} 16-17 \mathrm{~A}$ ). Their compositions are detailed in table 1, entries 1-7. 


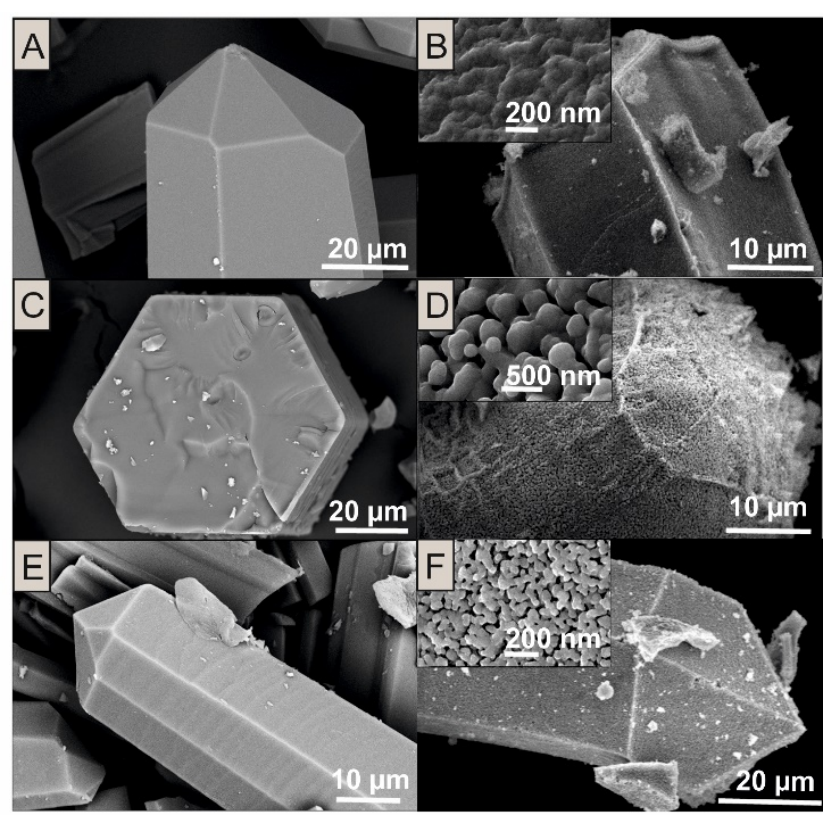

FIGURE 3. The figure shows MOF-crystal SEM pictures in the left column, and FESEM images of the corresponding calcined product, and its magnification images (x200,000), in the right column. A) $\mathrm{Zn}_{0.17} \mathrm{Mn}_{0.45} \mathrm{Co}_{0.48}$ (hfipbb) crystal SEM image; B) FESEM picture of corresponding calcined product with formula $\mathrm{Zn}_{0.51} \mathrm{Mn}_{1.35} \mathrm{Co}_{1.14} \mathrm{O}_{4}$; C) $\mathrm{Mn}_{0.23} \mathrm{Co}_{0.50} \mathrm{Ca}_{0.24}$ (hfipbb) crystal SEM image; D) FESEM picture of $\mathrm{Mn}_{0.23} \mathrm{Co}_{0.50} \mathrm{Ca}_{0.24}$ (hfipbb) calcined product resulting in a cubic spinel with formula $\mathrm{Mn}_{0.69} \mathrm{Co}_{1.50} \mathrm{Ca}_{0.81} \mathrm{O}_{4}$; E) $\mathrm{Zn}_{0.16} \mathrm{Mn}_{0.47} \mathrm{Co}_{0.33} \mathrm{Ca}_{0.03}$ (hfipbb) crystal SEM image; F) FESEM picture of calcined product of $\mathrm{Zn}_{\mathrm{O} .16} \mathrm{Mn}_{0.47} \mathrm{Co}_{0.33} \mathrm{Ca}_{\text {o.03 }}$ (hfipbb) resulting in a cubic spinel with formula $\mathrm{Zn}_{0.48} \mathrm{Mn}_{1.41} \mathrm{Co}_{0.99} \mathrm{Ca}_{0.09} \mathrm{O}_{4}$.
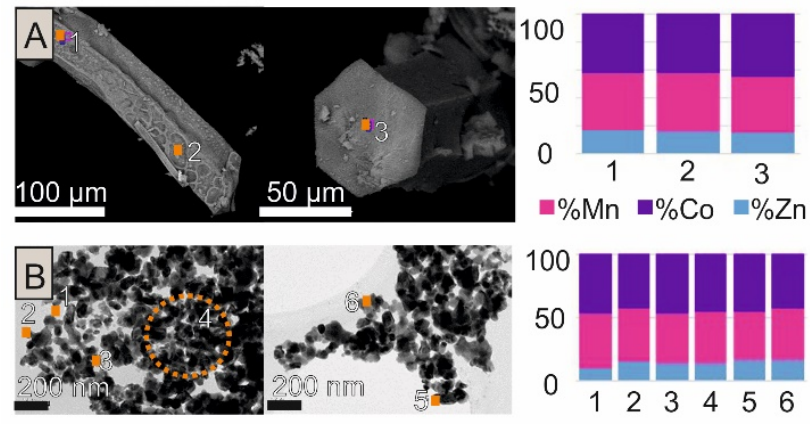

FIGURE 4. A) SEM-EDS analyses and B) TEM-EDS analyses from $\mathrm{Zn}_{0.36} \mathrm{Mn}_{1.26} \mathrm{Co}_{1.38} \mathrm{O}_{4}$ spinel. Orange spots indicate the areas where EDS were performed. Plot (right) shows the metal ratios by EDS analyses, where each column corresponds to the area indicated by a number in the SEM pictures.

In the case of ternary multi-metal MOFs prepared from molar codes including zinc, manganese, and calcium, spinel oxides were also formed, but mixed with wurtzite and to less extent with other crystalline phases that could not be unambiguously identified (figure S15-18). However, calcination of the MOF prepared from a molar code $\mathrm{Mn}: \mathrm{Co}: \mathrm{Ca}$ 1:2:2 also resulted in the obtaining of spinel type oxide as only phase (figure $5^{\mathrm{B}}$ and $\mathrm{S} 18 \mathrm{~F})$. In this case, as deduced from the experimentally determined formula of $\mathrm{Mn}_{0.69} \mathrm{Co}_{1.50} \mathrm{Ca}_{0.81} \mathrm{O}_{4}$, an inverse spinel should be formed, with cobalt atoms occupying tetrahedral sites, and manganese and calcium atoms at the octahedral sites.

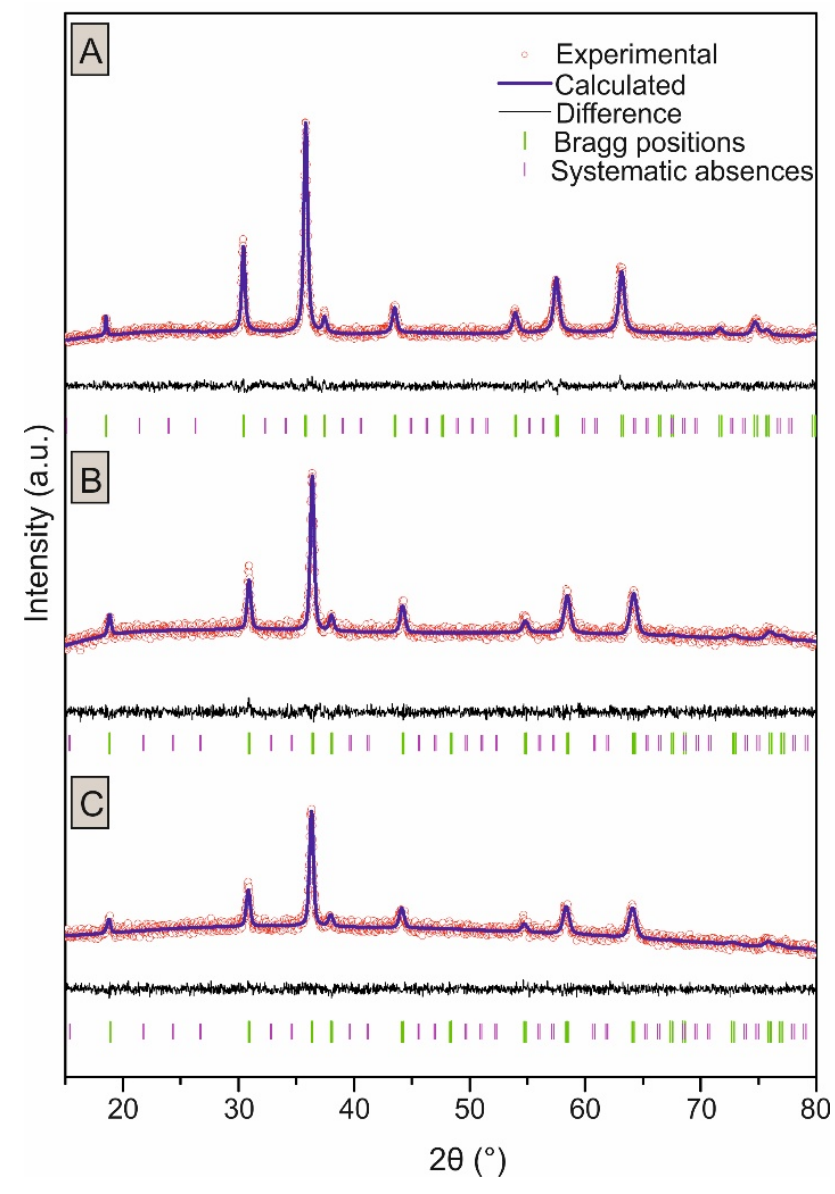

FIGURE 5. Full pattern profile refinement plot of $A$ ) $\mathrm{Zn}_{0.51} \mathrm{Mn}_{1.35} \mathrm{Co}_{1.14} \mathrm{O}_{4}$ spinel with $\mathrm{Fd}$-3m space group (a $=8.260$ $\AA$ ); B) $\mathrm{Mn}_{0.69} \mathrm{Col}_{.50} \mathrm{Ca}_{0.81} \mathrm{O}_{4}$ spinel with $\mathrm{Fd}$-3m space group (a = 8.211 $\AA$ ); C) $\mathrm{Zn}_{0.48} \mathrm{Mn}_{1.41} \mathrm{Co}_{0.99} \mathrm{Ca}_{0.09} \mathrm{O}_{4}$ spinel with $\mathrm{Fd}$-3m space group $(\mathrm{a}=8.306 \AA)$.

\section{Quaternary Zn:Mn:Co:Ca systems}

Multi-metal spinel oxides containing four elements were readily obtained by calcination of the selected quaternary multimetal MOFs. Thus, calcination of the MOF with composition $\mathrm{Zn}_{\text {o.42 }} \mathrm{Mn}_{\mathrm{O} .42} \mathrm{Co}_{\text {o.11 }} \mathrm{Ca}_{\mathrm{o} .06}$ (hfipbb) results in the obtaining of an oxide with cubic spinel structure (figure $\mathrm{S}_{17}$ ) and formula $\mathrm{Zn}_{1.26} \mathrm{Mn}_{1.26} \mathrm{Co}_{0.33} \mathrm{Ca}_{0.18} \mathrm{O}_{4}$, as determined by ICP analysis (figure $\mathrm{S}_{16}$ ). To the best of our knowledge, this is the first time that spinel oxides are obtained incorporating $\mathrm{Zn}, \mathrm{Mn}, \mathrm{Co}$, and Ca in their structure. Most importantly, different metal combinations initially programmed in the selected quaternary multi-metal MOFs could be translated to the spinel oxides (figures ${ }_{5} \mathrm{C}$ and $\mathrm{S}_{17-18}$ ). Thus, a series of eight tetra-cation spinel oxides with variable composition and general formula $\mathbf{Z n}_{\mathrm{w}} \mathbf{M n}_{\mathrm{x}} \mathbf{C o}_{\mathrm{y}} \mathrm{Ca}_{\mathrm{z}} \mathbf{O}_{4}$ have been obtained (table 1, entries 8-15), where $0.39<\mathrm{w}<1.26,0.72<\mathrm{x}<1.26,0.33<\mathrm{y}<1.56$, and $0.09<\mathrm{z}<0.66$. However, it should be noted that certain limitations for the obtaining of spinel as sole phase where observed regarding the combination of metal elements in the selected MOF. Thus, for MOFs with a low content of manganese, as in the case of the material prepared from molar code Zn:Mn:Co:Ca 1:1:4:8, presence of wurtzite and other crystal phases were detected in the PXRD pattern of the calcined solid, along with the spinel oxide (table S21, entry 30 and figure S18D). Conversely, when starting from a MOF with a large amount of zinc in the molar code 
(Zn:Mn:Co:Ca 2:1:2:2), wurtzite and another unknown phase were formed along with the spinel oxide (table S21, entry 27 and figure S18A). Interestingly, the maximum amount of zinc allowed for the obtaining of pure spinel oxides avoiding the appearance of wurtzite is larger in quaternary multi-metal MOFs than in ternary systems, demonstrating the importance of the initial cation arrangement of the MOF precursor on the structure of the obtained oxides. Nevertheless, we emphasize the suitability and wide applicability of this process to prepare a range of spinel type oxides with novel, desired compositions, easily translated from MOFs with programmable cation arrangements, with a simple calcination process.

\section{Evaluation of multi-metal spinel oxides as ORR elec- trocatalysts.}

Current benchmark catalysts for the ORR are based on the use of platinum, but metal scarcity, its high cost and inherent deactivation problems have fostered an intensive search for alternatives. As a result, a wide spectrum of materials such as transition metal-/metal oxide nanoparticles, ${ }^{25}$ perovskites, ${ }^{26}$ spinels and heteroatom doped $3 \mathrm{D}$ and $2 \mathrm{D}$ carbonaceous materials ${ }^{27}$ are being analyzed as substituting candidates. Among them, transition metal spinels show not only an affordable cost but also the most promising performance as both ORR and OER electrocatalysts. ${ }^{28}$ Among the list of transition metals employed, spinel materials based on $\mathrm{Mn}, \mathrm{Co}, \mathrm{Fe}$ and $\mathrm{Ni}$ have been widely studied due to their outstanding performance, which is strongly dependent on subtle changes in composition. For example, it has been proposed that in $\mathrm{Mn}_{\mathrm{x}} \mathrm{Co}_{3-\mathrm{x}} \mathrm{O}_{4}$ spinel oxides, the activity improves when $\mathrm{x} \leq \mathbf{2 . 0}$ because $\mathrm{Co}^{3+}$ and $\mathrm{Mn}^{3+}$ cations present an internal redox reaction that generates $\mathrm{Co}^{2+}$ and $\mathrm{Mn}^{4+}$ pairs, responsible for an increase in conductivity. ${ }^{29}$

Recently, the use of bimetallic Mn-Co MOFs to obtain multimetal-spinel oxides has been reported. However, other crystal phases might appear during the thermal treatment. ${ }^{30}$ In addition, when the spinels have been obtained as pure phases, differences in the structure were found depending on the amount of manganese and cobalt present, finding that mixed $\mathrm{Mn}_{\mathrm{x}} \mathrm{Co}_{3-\mathrm{x}} \mathrm{O}_{4}$ spinels with a high content of manganese have a tetragonal structure (space group $I_{4}-2 \mathrm{~m}$ ) while spinels rich in Co are cubic (space group $F d-3 m$ )..$^{31} \mathrm{Zn}$-Co multimetal MOFs have been used also to obtain cubic $\mathrm{Zn}$-Co spinel oxides. ${ }^{32}$

Following our methodology to translate compositional complexity from multi-metal MOFs to oxides, we have evaluated seventeen tri- and tetra-metallic spinel oxides with unprecedented compositions as electrocatalysts for ORR. First, we investigated the electrochemical activity of the samples towards the ORR by running cyclic voltammetry $(\mathrm{CV})$ in both $\mathrm{O}_{2}$ and $\mathrm{N}_{2}$ saturated electrolyte solutions. In all cases $\mathrm{CV}$ curves in $\mathrm{N}_{2}$ saturated electrolyte showed a quasi-rectangular shape without any redox peak (figures $\mathrm{S}_{30} \mathrm{O}-\mathrm{S}_{32}$ ) indicating the good stability of the materials in the studied potential window. Interestingly, voltammograms of all the samples in $\mathrm{O}_{2}$-saturated electrolyte exhibited a clear cathodic peak centered between 0.3 and $0.42 \mathrm{~V}$ probing the electrocatalytical activity of the samples (figures $\mathrm{S}_{30}$-S32). Even though all multi-metal spinel oxides show activity towards the ORR, they present a relatively large overpotential of $200-290 \mathrm{mV}$, as compared to that of the commercial $\mathrm{Pt} / \mathrm{C}$ catalyst. One approach to decrease the overpotential of a specific reaction is to load the active material in a more conductive support (e.g., carbon nanotubes, graphene) ${ }^{33-37}$ In the present study, samples were evaluated after being mixed with active carbon and Nafion as a binder. However, given no strong coupling between the carbon and the active material (in this case the MOF derived spinel) no major change in the local electron transfer was expected and thus, the overpotential was still large. ${ }^{37}$

The Koutecky-Levich (K-L) plots obtained from the correspondent LSVs at different rotation speeds present a good linearity, indicating that current was mainly kinetically controlled (figures $\mathrm{S}_{33}-\mathrm{S}_{3} 8$ ). Table 1 summarizes the number of transferred electrons ( $\mathrm{Ne}$, obtained from the K-L analysis), and the current density of each sample expressed as \% of current density measured for commercial $\mathrm{Pt} / \mathrm{C}(20 \% \mathrm{w})$. The systematic translation of compositional complexity from multimetal MOFs to oxides allows extracting important information when the evaluation of the sample compositions is done. Thus, analysis of $\mathrm{Zn}-\mathrm{Co}-\mathrm{Mn}$ spinels, including solids with $\quad \mathrm{Zn}_{0.36} \mathrm{Mn}_{1.26} \mathrm{Co}_{1.38} \mathrm{O}_{4}, \quad \mathrm{Zn}_{\text {o.66 }} \mathrm{Mn}_{\text {o.96 }} \mathrm{Co}_{1.38} \mathrm{O}_{4}$, $\mathrm{Zn}_{\text {o.69 }} \mathrm{Mn}_{1.32} \mathrm{Co}_{0.99} \mathrm{O}_{4}, \mathrm{Zn}_{0.51} \mathrm{Mn}_{1.23} \mathrm{Co}_{1.26} \mathrm{O}_{4}, \mathrm{Zn}_{0.36} \mathrm{Mn}_{1.17} \mathrm{Co}_{1.47} \mathrm{O}_{4}$, $\mathrm{Zn}_{0.30} \mathrm{Mn}_{1.20} \mathrm{Co}_{1.50} \mathrm{O}_{4}$ and $\mathrm{Zn}_{0.51} \mathrm{Mn}_{1.35} \mathrm{Co}_{1.14} \mathrm{O}_{4}$ composition (Table 1 entries 1 to 7 ), evidences a strong influence of the ratios of all three different elements on the catalytic performance. A simple correlation between composition variation and activity is not evident, and rather a complex behavior is observed. Recently, ${ }^{36}$ a correlation between the $\mathrm{Mn} / \mathrm{Co}$ ratio and electrocatalytic activity due to superexchange effects between the octahedral sites has been reported for $\mathrm{Zn}: \mathrm{Co}: \mathrm{Mn}$ spinels where the tetrahedral sites are occupied by zinc. In our case, the tetrahedral sites are occupied not only by zinc, due to the sample metal ratios, and thus other effects should also influence the catalytic activity. We are currently investigating the distribution of the metal cations in the spinel structure to determine the occupancy of each site. Nevertheless, we have found that samples containing the three metal elements (i.e., $\mathrm{Zn}, \mathrm{Mn}$ and $\mathrm{Co}$ ) also exhibited a major contribution of the $4 \mathrm{e}$ transfer mechanism and larger current densities (see Figure 6). Among the evaluated samples, the oxide with $\mathrm{Zn}_{0.51} \mathrm{Mn}_{1.35} \mathrm{Co}_{1.14} \mathrm{O}_{4}$ composition (table 1, entry 7) demonstrated the best performance, with a high limiting current density value (91.4\% of that found for commercial Pt based catalysts) and a number of transferred electrons close to four (3.80).

When comparing these results with the performance of the trimetallic sample containing $\mathrm{Mn}, \mathrm{Co}$ and $\mathrm{Ca}$ $\left(\mathrm{Mn}_{0.69} \mathrm{Co}_{1.50} \mathrm{Ca}_{0.81} \mathrm{O}_{4}\right.$, table 1 , entry $\left.{ }_{17}\right)$, we realized that this spinel also exhibited an excellent behavior as catalyst in the ORR with a slightly lower current density of $87.2 \%$ compared with $\mathrm{Pt} / \mathrm{C}(2 \mathrm{O} \mathrm{wt} \%)$ and a large contribution of the 4 electron transfer mechanism (Ne of 3.82) (Figure 7a). Despite calcium as such is not active towards the ORR, its presence in the spinel structure influences the overall activity. For example, it may enhance $\mathrm{O}_{2}$ adsorption, ${ }^{37}$ and moreover, calcium cations should be exclusively occupying octahedral sites (unlike Zn which preferentially occupies tetrahedral sites), therefore inducing the inversion of the spinel structure and altering $\mathrm{Mn}$ and Co oxidation states. ${ }^{38}$ Furthermore, when comparing with 
Table 1. The starting molar codes, corresponding MOFs, spinel formula, electron tranfer number (Ne), calculated from the slope of their Koutechy-Levich plot in ORR, and current density are shown in columns 2, 3, 4, 5, and 6, respectively. Entries 1-2 MOFs were prepared according to reference ${ }^{12}$.

\begin{tabular}{|c|c|c|c|c|c|c|c|c|}
\hline \multirow{2}{*}{ Entry } & \multicolumn{4}{|c|}{ Molar Code } & \multirow{2}{*}{ MOF formula } & \multirow{2}{*}{ Spinel formula } & \multirow{2}{*}{$\mathrm{Ne}$} & \multirow{2}{*}{$\begin{array}{c}\text { Current } \\
\text { density } \\
(\%)\end{array}$} \\
\hline & $\mathbf{Z n}$ & Mn & Co & Ca & & & & \\
\hline 1 & 1 & 1 & 8 & o & $\mathrm{Zn}_{0.22} \mathrm{Mn}_{0.32} \mathrm{Co}_{0.46}(\mathrm{hfipbb})$ & $\mathrm{Zn}_{0.66} \mathrm{Mn}_{0.96} \mathrm{Co}_{1.38} \mathrm{O}_{4}$ & 2.88 & 67.9 \\
\hline 2 & 1 & 3 & 9 & o & $\mathrm{Zn}_{0.12} \mathrm{Mn}_{0.42} \mathrm{Co}_{0.46}(\mathrm{hfipbb})$ & $\mathrm{Zn}_{0.36} \mathrm{Mn}_{1.26} \mathrm{Co}_{1.38} \mathrm{O}_{4}$ & 3.81 & 73.8 \\
\hline 3 & 1 & 4 & 4 & o & $\mathrm{Zn}_{0.23} \mathrm{Mn}_{\mathrm{o.44}} \mathrm{Co}_{0.33}(\mathrm{hfipbb})$ & $\mathrm{Zn}_{0.69} \mathrm{Mn}_{1.32} \mathrm{Co}_{0.99} \mathrm{O}_{4}$ & 3.03 & 70.6 \\
\hline 4 & 1 & 4 & 6 & o & $\mathrm{Zn}_{0.17} \mathrm{Mn}_{0.41} \mathrm{Co}_{0.42}(\mathrm{hfipbb})$ & $\mathrm{Zn}_{0.51} \mathrm{Mn}_{1.23} \mathrm{Co}_{1.26} \mathrm{O}_{4}$ & 3.09 & 71.7 \\
\hline 5 & 1 & 6 & 12 & o & $\mathrm{Zn}_{\text {o.12 }} \mathrm{Mn}_{0.39} \mathrm{Co}_{0.49}(\mathrm{hfipbb})$ & $\mathrm{Zn}_{0.36} \mathrm{Mn}_{1.17} \mathrm{Co}_{1.47} \mathrm{O}_{4}$ & 3.06 & 63.4 \\
\hline 6 & 1 & 10 & 20 & o & $\mathrm{Zn}_{\text {o.10 }} \mathrm{Mn}_{0.40} \mathrm{Co}_{0.50}(\mathrm{hfipbb})$ & $\mathrm{Zn}_{0.30} \mathrm{Mn}_{1.20} \mathrm{Co}_{1.50} \mathrm{O}_{4}$ & 3.56 & 86.6 \\
\hline 7 & 1 & 12 & 6 & o & $\mathrm{Zn}_{0.17} \mathrm{Mn}_{0.45} \mathrm{Co}_{0.38}$ (hfipbb) & $\mathrm{Zn}_{0.51} \mathrm{Mn}_{1.35} \mathrm{Co}_{1.14} \mathrm{O}_{4}$ & 3.80 & 91.4 \\
\hline 8 & 1 & 1 & 1 & 1 & $\mathrm{Zn}_{0.42} \mathrm{Mn}_{\text {o.42 }} \mathrm{Co}_{0.11} \mathrm{Ca}_{\text {o.o6 }}(\mathrm{hfipbb})$ & $\mathrm{Zn}_{1.26} \mathrm{Mn}_{1.26} \mathrm{Co}_{0.33} \mathrm{Ca}_{0.18} \mathrm{O}_{4}$ & 3.10 & 102.3 \\
\hline 9 & 1 & 1 & 7 & 1 & $\mathrm{Zn}_{0.13} \mathrm{Mn}_{0.27} \mathrm{Co}_{0.52} \mathrm{Ca}_{0.03}$ (hfipbb) & $\mathrm{Zn}_{0.39} \mathrm{Mn}_{0.81} \mathrm{Co}_{1.56} \mathrm{Ca}_{0.09} \mathrm{O}_{4}$ & 3.64 & 73.4 \\
\hline 10 & 1 & 4 & 4 & 1 & $\mathrm{Zn}_{0.16} \mathrm{Mn}_{0.47} \mathrm{Co}_{0.33} \mathrm{Ca}_{0.03}$ (hfipbb) & $\mathrm{Zn}_{0.48} \mathrm{Mn}_{1.41} \mathrm{Co}_{0.99} \mathrm{Ca}_{0.09} \mathrm{O}_{4}$ & 3.92 & 97.2 \\
\hline 11 & 1 & 1 & 4 & 4 & $\mathrm{Zn}_{0.18} \mathrm{Mn}_{0.24} \mathrm{Co}_{0.41} \mathrm{Ca}_{0.16}(\mathrm{hfipbb})$ & $\mathrm{Zn}_{0.54} \mathrm{Mn}_{0.72} \mathrm{Co}_{1.23} \mathrm{Ca}_{0.48} \mathrm{O}_{4}$ & 2.76 & 65.6 \\
\hline 12 & 1 & 4 & 4 & 4 & $\mathrm{Zn}_{0.24} \mathrm{Mn}_{0.37} \mathrm{Co}_{0.31} \mathrm{Ca}_{0.08}($ hfipbb) & $\mathrm{Zn}_{0.72} \mathrm{Mn}_{1.11} \mathrm{Co}_{0.93} \mathrm{Ca}_{0.24} \mathrm{O}_{4}$ & 3.91 & 79.9 \\
\hline 13 & 1 & 4 & 1 & 4 & $\mathrm{Zn}_{0.32} \mathrm{Mn}_{0.40} \mathrm{Co}_{0.15} \mathrm{Ca}_{0.12}(\mathrm{hfipbb})$ & $\mathrm{Zn}_{0.96} \mathrm{Mn}_{1.20} \mathrm{Co}_{0.45} \mathrm{Ca}_{0.36} \mathrm{O}_{4}$ & 3.06 & 80.3 \\
\hline 14 & 1 & 2 & 2 & 4 & $\mathrm{Zn}_{0.27} \mathrm{Mn}_{0.34} \mathrm{Co}_{0.26} \mathrm{Ca}_{0.12}$ (hfipbb) & $\mathrm{Zn}_{0.81} \mathrm{Mn}_{1.02} \mathrm{Co}_{0.78} \mathrm{Ca}_{0.36} \mathrm{O}_{4}$ & 3.41 & 72.9 \\
\hline 15 & 1 & 4 & 4 & 8 & $\mathrm{Zn}_{0.21} \mathrm{Mn}_{0.27} \mathrm{Co}_{0.30} \mathrm{Ca}_{0.22}$ (hfipbb) & $\mathrm{Zn}_{0.63} \mathrm{Mn}_{0.81} \mathrm{Co}_{0.90} \mathrm{Ca}_{0.66} \mathrm{O}_{4}$ & 2.72 & 67.9 \\
\hline 16 & o & 1 & 1 & o & $\mathrm{Mn}_{\mathrm{o} .41} \mathrm{Co}_{\mathrm{o} .59}($ hfipbb $)$ & $\mathrm{Mn}_{1.23} \mathrm{Co}_{1.77} \mathrm{O}_{4}$ & 3.22 & 75.7 \\
\hline 17 & $\mathrm{o}$ & 1 & 2 & 2 & $\mathrm{Mn}_{0.23} \mathrm{Co}_{0.50} \mathrm{Ca}_{0.27}(\mathrm{hfipbb})$ & $\mathrm{Mn}_{0.69} \mathrm{Co}_{1.50} \mathrm{Ca}_{0.81} \mathrm{O}_{4}$ & 3.82 & 87.2 \\
\hline 18 & & $\mathrm{Pt} / \mathrm{C}($ & $\% \mathrm{~W}$ & & & & 3.67 & 100 \\
\hline
\end{tabular}

the bimetallic Mn-Co spinel (table 1, entry 16), it becomes apparent that in this case the presence of calcium atoms improves the performance in terms of both current density and number of electrons.

Following we sought to study the performance of the newly prepared spinel oxides incorporating four different cations. At the view of the results of the tested materials, we noticed that the solid with the highest content of calcium did not show any improvement compared to the previously evaluated materials. Thus, the spinel with composition $\mathrm{Zn}_{0.63} \mathrm{Mn}_{0.81} \mathrm{Co}_{0.90} \mathrm{Ca}_{0.66} \mathrm{O}_{4}$ (table 1, entry 15) showed a current density of $67.9 \%$ and 2.72 electrons. Similarly, the sample with $\mathrm{Zn}_{0.54} \mathrm{Mn}_{0.72} \mathrm{Co}_{1.23} \mathrm{Ca}_{0.48} \mathrm{O}_{4}$ formula exhibited a current density of $65.6 \%$ and 2.76 electrons. These results seem to evidence that a large amount of calcium in the structure is detrimental for the electrocatalytic performance, with a low electron number that indicates that a two-electron process is dominant. However, we found that a fine adjustment of the oxide composition results in a significant improvement in current density. Thus, the oxide with $\mathrm{Zn}_{0.48} \mathrm{Mn}_{1.41} \mathrm{Co}_{0.99} \mathrm{Ca}_{0.09} \mathrm{O}_{4}$ formula (table 1, entry 10 ) demonstrated the best behavior among all the seventeen tested materials, with a current density of $\mathbf{9 7 . 2} \%$ and an electron transfer number of 3.92. This value is among the best obtained for spinel oxides employed as ORR electrocatalysts without additional processing or composite fabrication. 


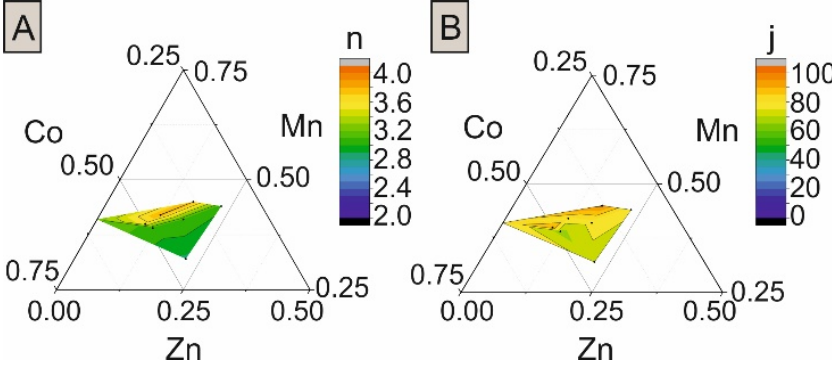

FIGURE 6. Ternary composition graph of zinc-manganesecobalt spinels showing A) transferred electron number (n) and B) current density (j).

Both long term stability and methanol tolerance are important drawbacks of commercial Pt-based catalysts. ${ }^{39}$ Thus, in order to compare our results, we also studied stability as well as tolerance towards methanol crossover of the spinel oxides showing the best catalytic activity. Stability was evaluated by performing a chronoamperometry in saturated $\mathrm{O}_{2} \mathrm{KOH}$ o.1 M electrolyte at 1600 rpm for $5000 \mathrm{~s}$. The results show that all the new materials outperform Pt based catalyst in stability terms showing a slight current attenuation of less than $8 \%$ (figure 7b). The methanol crossover test also showed that for all tested spinel oxides, the current is altered in less than a $4 \%$ after the addition of methanol. In contrast, methanol addition when using the commercial $\mathrm{Pt} / \mathrm{C}$ catalyst promoted a sharp drop of the current response of $c a .70 \%$ (Figure $7 \mathrm{~b}$ ).

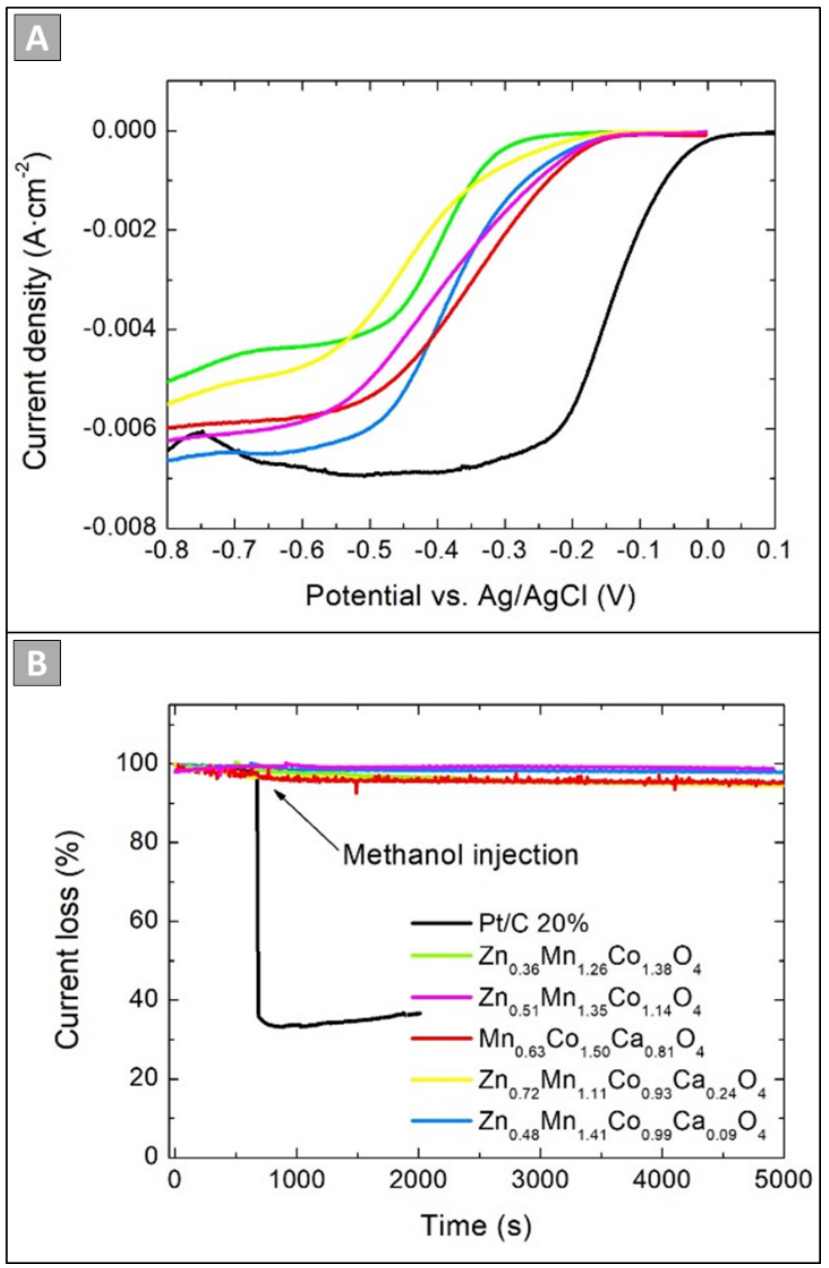

FIGURE 7. Results of the electrocatalytic ORR study. comparing commercial $\mathrm{Pt} / \mathrm{C}$ (20\%) (black), and spinels with composition $\mathrm{Zn}_{0.36} \mathrm{Mn}_{1.26} \mathrm{Co}_{1.38} \mathrm{O}_{4}$ (green), $\mathrm{Zn}_{0.51} \mathrm{Mn}_{1.35} \mathrm{Co}_{1.14} \mathrm{O}_{4}$ (pink), $\mathrm{Mn}_{0.69} \mathrm{Co}_{1.50} \mathrm{Ca}_{0.81} \mathrm{O}_{4}, \mathrm{Zn}_{0.72} \mathrm{Mn}_{1.11} \mathrm{Co}_{0.93} \mathrm{Ca}_{0.24} \mathrm{O}_{4}$ (yellow) and $\mathrm{Zn}_{0.48} \mathrm{Mn}_{1.41} \mathrm{Co}_{0.99} \mathrm{Ca}_{0.09} \mathrm{O}_{4}$ (blue), A) Comparison of ORRLSV curves of mixed-metal spinel type oxides prepared from multi-metal MOFs in a $\mathrm{O}_{2}$-saturated o.1 $\mathrm{M} \mathrm{KOH}$ solution stirred at $2000 \mathrm{rpm}$; B) Comparison of methanol crossover in a $\mathrm{O}_{2}$-saturated in o.1 $\mathrm{M} \mathrm{KOH}$ electrolyte stirred at $1600 \mathrm{rpm}$ with methanol injection at 6oos.

\section{SUMMARY}

In summary, new isoreticular MOFs with different arrangements of up to four metal-cations have been realized through the adjustment of the selected molar codes. The resulting metal ratios are preserved through the MOF calcination processes, resulting in the ability to program new compositions in spinel type oxides, as proved with the 17 new multi-metal oxides prepared and characterized. We show that the incorporation of multiple metal elements results in a complex interplay, where small modifications in metal ratios strongly influence the electrocatalytical activity in the oxygen reduction reaction, both in terms of current density, and number of transferred electrons. Thus, the material with composition $\mathrm{Zn}_{\mathrm{O} .48} \mathrm{Mn}_{1.41} \mathrm{Co}_{0.99} \mathrm{Ca}_{0.09} \mathrm{O}_{4}$ that is programmed from a MOF prepared from a $\mathrm{Zn}: \mathrm{Co}: \mathrm{Mn}: C a$ 1:4:4:1 molar code, achieves a current density that is $97.2 \%$ that of commercial $\mathrm{Pt} / \mathrm{C}(20 \% \mathrm{~W})$ catalyst, with a 3.92 electron process. These results demonstrate the potential to program and attain new compositions through the selection of adequate molar codes in complex multi-metal MOFs.

\section{ASSOCIATED CONTENT}

\section{SUPPORTING INFORMATION.}

Supporting figures and tables, single crystal X-ray results, SEM-EDS, TEM-EDS, FE-SEM images, powder X-ray diffraction patterns, powder neutron diffraction patterns and Rietveld refinements, TGA plots, CV curves, K-L plots and LSV curves. This material is available free of charge via the Internet at http://pubs.acs.org.

\section{AUTHOR INFORMATION}

\section{Corresponding Author}

* gandara@icmm.csic.es

* amonge@icmm.csic.es

\section{Author Contributions}

The manuscript was written through contributions of all authors.

\section{Funding Sources \\ MAT2016-78465-R, MAT2015-68639-R and CTQ2017-87262-R}

\section{ACKNOWLEDGMENT}

We acknowledge Institut Laue-Langevin and Spanish Initiatives on Neutron Scattering (ILL- SpINS) for beamtime at instrument DiB and G. Cuello for assistance during data acqui- 
sition. Paul Scherrer Institute is also acknowledged for beamtime at instrument HRPT, V. Pomjakhusin for assistance during data acquisition. We thank E. Rodríguez-Cañas and Isidoro Poveda from the Servicio Interdepartamental de Investigación at Universidad Autónoma de Madrid for valuable support with SEM images and EDS analyses and FE-SEM images acquisition, respectively. We acknowledge E. Urones for the TEM images and TEM-EDS analyses acquisition at Centro Nacional de Microscopía Electrónica. Funding: Work at Instituto de Ciencia de Materiales de Madrid-Consejo Superior de Investigaciones Científicas (CSIC) has been supported by the Spanish Ministry for Science, Innovation and Universities (MINECO) and FEDER funds: Projects MAT2016-78465-R, MAT2015-68639-R and CTQ2017-87262-R. F.G. and N.L.-S. acknowledge financial support from MINECO (Ramón y Cajal program and FPI research contract, respectively).

\section{REFERENCES}

1. Castillo-Blas, C.; Snejko, N.; de la Peña-O'Shea, V. A.; Gallardo, J.; Gutiérrez-Puebla, E.; Monge, M. A.; Gándara, F., Crystal phase competition by addition of a second metal cation in solid solution metal-organic frameworks. Dalton Transactions 2016, 45 (10), 4327-4337.

2. $\quad$ D'Vries, R. F.; Alvarez-García, S.; Snejko, N.; Bausá, L. E.; Gutiérrez-Puebla, E.; de Andrés, A.; Monge, M. A., Multimetal rare earth MOFs for lighting and thermometry: tailoring color and optimal temperature range through enhanced disulfobenzoic triplet phosphorescence. Journal of Materials Chemistry C 2013, 1 (39), 6316-6324.

3. $\quad$ Furukawa, H.; Cordova, K. E.; O’Keeffe, M.; Yaghi, O. M., The Chemistry and Applications of Metal-Organic Frameworks. Science 2013, 341 (6149).

4. Yuan, S.; Chen, Y. P.; Qin, J.; Lu, W.; Wang, X.; Zhang, Q.; Bosch, M.; Liu, T. F.; Lian, X.; Zhou, H. C., Cooperative Cluster Metalation and Ligand Migration in Zirconium Metal-Organic Frameworks. Angewandte Chemie International Edition 2015, 54 (49), 14696-1470o.

5. Brozek, C. K.; Dincă, M., Cation exchange at the secondary building units of metal-organic frameworks. Chemical Society Reviews 2014, 43 (16), 5456-5467.

6. Castells-Gil, J.; Padial, N. M.; Almora-Barrios, N.; Albero, J.; Ruiz-Salvador, A. R.; González-Platas, J.; García, H.; Martí-Gastaldo, C., Chemical Engineering of Photoactivity in Heterometallic Titanium-Organic Frameworks by Metal Doping. Angewandte Chemie International Edition 2018, 57 (28), 8453-8457.

7. Wang, L. J.; Deng, H.; Furukawa, H.; Gándara, F.; Cordova, K. E.; Peri, D.; Yaghi, O. M., Synthesis and Characterization of Metal-Organic Framework-74 Containing 2, 4, 6, 8, and 1o Different Metals. Inorganic Chemistry 2014, 53 (12), 5881-5883.

8. Zhai, Q.-G.; Bu, X.; Mao, C.; Zhao, X.; Feng, P., Systematic and Dramatic Tuning on Gas Sorption Performance in Heterometallic Metal-Organic Frameworks. Journal of the American Chemical Society 2016, 138 (8), 2524-2527.

9. Liu, Z.-F.; Wu, M.-F.; Wang, S.-H.; Zheng, F.-K.; Wang, G.-E.; Chen, J.; Xiao, Y.; Wu, A. Q.; Guo, G.-C.; Huang, J.-S., Eu ${ }^{3+}$ doped $\mathrm{Tb}^{3+}$ metal-organic frameworks emitting tunable three primary colors towards white light. Journal of Materials Chemistry $C$ 2013, 1 (31), 4634-4639.

10. Sapnik, A.F.; Gedes, H.S.; Reynolds, E.M.; Yeung, H.H.M; Goodwin, A.L., Compositional inhomogeneity and tuneable thermal expansion in mixed-metal ZIF-8 analogues. Chemical Communications 2018, 54, 9651-9654.

11. Aguirre-Díaz, L. M.; Gándara, F.; Iglesias, M.; Snejko, N.; Gutiérrez-Puebla, E.; Monge, M. Á., Tunable Catalytic Activity of
Solid Solution Metal-Organic Frameworks in One-Pot Multicomponent Reactions. Journal of the American Chemical Society 2015, 137 (19), 6132-6135.

12. Liu, Q.; Cong, H.; Deng, H., Deciphering the Spatial Arrangement of Metals and Correlation to Reactivity in Multivariate Metal-Organic Frameworks. Journal of the American Chemical Society 2016, 138, 13822-13825.

13. Castillo-Blas, C.; de la Peña-O'Shea, V. A.; PuenteOrench, I.; de Paz, J. R.; Sáez-Puche, R.; Gutiérrez-Puebla, E.; Gándara, F.; Monge, Á., Addressed realization of multication complex arrangements in metal-organic frameworks. Science Advances 2017, 3 (7), 1700773.

14. Qian, Y.; Khan Inayat, A.; Zhao, D., Electrocatalysts Derived from Metal-Organic Frameworks for Oxygen Reduction and Evolution Reactions in Aqueous Media. Small 2017, 13 (37), 1701143. 15. Liu, B.; Shioyama, H.; Jiang, H.; Zhang, X.; Xu, Q., Metal-organic framework (MOF) as a template for syntheses of nanoporous carbons as electrode materials for supercapacitor. Carbon 2010, 48 (2), 456-463.

16. Dang, S.; Zhu, Q.-L.; Xu, Q., Nanomaterials derived from metal-organic frameworks. Nature Reviews Materials 2017, 3, 17075 .

17. Wu, H.; Zhou, W.; Yildirim, T., Hydrogen Storage in a Prototypical Zeolitic Imidazolate Framework-8. Journal of the American Chemical Society 2007, 129 (17), 5314-5315.

18. Choi, K. M.; Jeong, H. M.; Park, J. H.; Zhang, Y.-B.; Kang, J. K.; Yaghi, O. M., Supercapacitors of Nanocrystalline Metal-Organic Frameworks. ACS Nano 2014, 8 (7), 7451-7457.

19. Yang, H.; Bradley, S. J.; Wu, X.; Chan, A.; Waterhouse, G. I. N.; Nann, T.; Zhang, J.; Kruger, P. E.; Ma, S.; Telfer, S. G., General Synthetic Strategy for Libraries of Supported Multicomponent Metal Nanoparticles. ACS Nano 2018, 12 (5), 4594-46o4.

2o. Yazdi, A.; Abo Markeb, A.; Garzón-Tovar, L.; Patarroyo, J.; Moral-Vico, J.; Alonso, A.; Sánchez, A.; Bastus, N.; Imaz, I.; Font, X.; Puntes, V.; Maspoch, D., Core-shell $\mathrm{Au} / \mathrm{CeO}_{2}$ nanoparticles supported in $\mathrm{UiO}-66$ beads exhibiting full $\mathrm{CO}$ conversion at $100{ }^{\circ} \mathrm{C}$. Journal of Materials Chemistry A 2017, 5 (27), 13966-13970. 21. Dolomanov, O.V.; Bourhis, L.J.; Gildea, R.J.; Howard, J.A.K.; Puschmann, H., OLEX2: A complete structure solution, refinement and analysis program. Journal of Applied Crystallography 2009, 42, 339-341.

22. Sheldrick, G.M., A short history of SHELX. Acta Crystallographica A 2008, 64, 112-122.

23. Monge, A.; Snejko, N.; Gutierrez-Puebla, E.; Medina, M.; Cascales, C.; Ruiz-Valero, C.; Iglesias, M.; Gomez-Lor, B., One teflon-like channelled nanoporous polymer with a chiral and new uninodal 4-connected net: sorption and catalytic properties. Chemical Communications 2005, (10), 1291-1293.

24. Sun, J.-K.; Xu, Q., Functional materials derived from open framework templates/precursors: synthesis and applications. Energy \& Environmental Science 2014, 7 (7), 2071-2100.

25. Toh, R.J.; Eng, A.Y.S.; Safer, Z.; Sedmidubsky, S; Pumera, D., Ternary Transition Metal Oxide nanoparticles with Spinel Structure for the Oxygen Reduction Reaction. ChemElectroChem 2015, 2,982-987.

26. Jiang, S.; Liang, F.; Zhou, W.; Shao, Z, Hierarchical porous cobalt-free perovskite electrode for highly efficient oxygen reduction. Journal of Materials Chemistry 2012, 22, 16214-16218.

27. Oderairo, T.; Yan, X.; Ma, J.; Jiao, Y.; Yao, X.; Du, A.; Zhu, Z., Nanosheets $\mathrm{Co}_{3} \mathrm{O}_{4}$ Interleaved with Graphene for Highly Efficient Oxygen Reduction. Applied Materials $\mathcal{E}$ Interfaces 2015, 7 , 21373-21380.

28. Zhao, Q.; Yan, Z.; Chen, C.; Chen, J., Spinels: Controlled Preparation, Oxygen Reduction/Evolution Reaction Application, and Beyond. Chemical Reviews 2017, 117 (15), 10121-10211. 
29. Lee, E.; Jang, J.-H.; Kwon, Y.-U., Composition effects of spinel $\mathrm{Mn}_{\mathrm{x}} \mathrm{Co}_{3-\mathrm{x}} \mathrm{O}_{4}$ nanoparticles on their electrocatalytic properties in oxygen reduction reaction in alkaline media. Journal of Power Sources 2015, 273, p 735-741.

30. $\quad$ Yao, L.; Yang, W.; Liu, H.; Jia, J.; Wu, G.; Liu, D.; Liu, T.; Tan, T.; Wang, C., Synthesis and ORR electrocatalytic activity of mixed Mn-Co oxides derived from divalent metal-based MIL-53 analogues. Dalton Transactions 2017, 46 (44), 15512-15519.

31. Mahata, P.; Sarma, D.; Madhu, C.; Sundaresen, A.; Natarajan, $\mathrm{S}$., $\mathrm{CoMn}_{2} \mathrm{O}_{4}$ spinel from a MOF: synthesis, structure and magnetic studies. Dalton Transactions 2011, 40 (9), 1952-1960.

32. Chen, S.; Xue, M.; Li, Y.; Pan, Y.; Zhu, L.; Zhang, D.; Fang, Q.; Qiu, S., Porous $\mathrm{ZnCo}_{2} \mathrm{O}_{4}$ nanoparticles derived from a new mixed-metal organic framework for supercapacitors. Inorganic Chemistry Frontiers 2015, 2 (2), 177-183.

33. Wu, Z.-S.; Yang, S.; Sun, Y.; Parvez, K.; Feng, X.; Müllen, K., $3 \mathrm{D}$ Nitrogen-Doped Graphene Aerogel-Supported $\mathrm{Fe}_{3} \mathrm{O}_{4} \mathrm{Na}-$ noparticles as Efficient Electrocatalysts for the Oxygen Reduction Reaction. Journal of the American Chemical Society 2012, 134 (22), 9082-9085.

34. $\quad$ Liang, Y.; Li, Y.; Wang, H.; Zhou, J.; Wang, J.; Regier, T.; Dai, $\mathrm{H}$., $\mathrm{CO}_{3} \mathrm{O}_{4}$ nanocrystals on graphene as a synergistic catalyst for oxygen reduction reaction. Nature Materials 2011, 10, 780 .
35. Li, C.; Han, X.; Cheng, F.; Hu, Y.; Chen, C.; Chen, J., Phase and composition controllable synthesis of cobalt manganese spinel nanoparticles towards efficient oxygen electrocatalysis. Nature Communications 2015, 6, 7345.

36. Zhou, Y.; Sun, S.; Xi, S.; Duan, Y.; Sritharan, T.; Du, Y.; $\mathrm{Xu}, \mathrm{Z}$.J., Superexchange Effects on Oxygen Reduction Activity of Edge-Sharing $\left[\mathrm{Co}_{\mathrm{x}} \mathrm{Mn}_{1-\mathrm{x}} \mathrm{O}_{6}\right]$ Octahedra in Spinel Oxide. Advanced Materials 2018, 30, 1705407.

37. Han, X.; Zhang, T.; Du, J.; Cheng, F.; Chen, J., Porous calcium-manganese oxide microspheres for electrocatalytic oxygen reduction with high activity. Chemical Science 2013, 4 (1), 368 376.

38. Wu, G.; Wang, J.; Ding, W.; Nie, Y.; Li, L.; Qi, X.; Chen, S.; Wei, Z., A strategy to promote the electrocatalytic activity of spinels dor oxygen reduction by structure reversal. Angewandte Chemie International Edition 2016, 55, 1340-1344.

39. Sa, Y. J.; Kwon, K.; Cheon, J. Y.; Kleitz, F.; Joo, S. H., Ordered mesoporous $\mathrm{Co}_{3} \mathrm{O}_{4}$ spinels as stable, bifunctional, noble metal-free oxygen electrocatalysts. Journal of Materials Chemistry A 2013, 1 (34), 9992-10001. 